\title{
Trends and outcome of neoadjuvant treatment for rectal cancer: A retrospective analysis and critical assessment of a 10 -year prospective national registry on behalf of the Spanish Rectal Cancer Project ${ }^{\text {ir }}$
}

\author{
Gianluca Pellino a, b, Rafael Alós a, Sebastiano Biondo ${ }^{c}$, Antonio Codina-Cazador ${ }^{\mathrm{d}}$, \\ José María Enríquez-Navascues ${ }^{\mathrm{e}}$, Eloy Espín-Basany ${ }^{\mathrm{b}}$, José Vicente Roig-Vila ${ }^{\mathrm{f}}$,

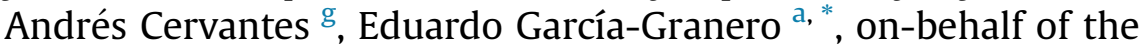 \\ Spanish Rectal Cancer Project collaborators \\ a Colorectal Unit, Hospital Universitario y Politecnico La Fe, University of Valencia, Spain \\ ${ }^{\mathrm{b}}$ Department of General Surgery, Colorectal Surgery Unit, Hospital Valle de Hebron, Autonomous University of Barcelona, Barcelona, Spain

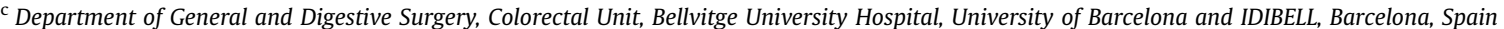 \\ ${ }^{\mathrm{d}}$ Department of General and Digestive Surgery-Colorectal Unit, Josep Trueta University Hospital, Girona, Spain \\ e General and Digestive Surgery Department, Donostia University Hospital, Donostia, Spain \\ ${ }^{\mathrm{f}}$ Unit of Coloproctology, Hospital Vithas-Nisa 9 de Octubre, Valencia, Spain \\ ${ }^{g}$ CIBERONC, Biomedical Research Institute INCLIVA, University of Valencia, Spain
}

\section{A R T I C L E I N F O}

Article history:

Accepted 30 April 2020

Available online $\mathrm{xxx}$

\section{Keywords:}

Rectal cancer

T stage

TNM

Prognosis

Neoadjuvant treatment

Survival

Radiotherapy

Chemotherapy

\begin{abstract}
A B S T R A C T
Introduction: Preoperative treatment and adequate surgery increase local control in rectal cancer. However, modalities and indications for neoadjuvant treatment may be controversial. Aim of this study was to assess the trends of preoperative treatment and outcomes in patients with rectal cancer included in the Rectal Cancer Registry of the Spanish Associations of Surgeons.

Method: This is a STROBE-compliant retrospective analysis of a prospective database. All patients operated on with curative intention included in the Rectal Cancer Registry were included. Analyses were performed to compare the use of neoadjuvant/adjuvant treatment in three timeframes: I)2006-2009; II) 2010-2013; III)2014-2017. Survival analyses were run for 3-year survival in timeframes I-II.

Results: Out of 14,391 patients,8871 (61.6\%) received neoadjuvant treatment. Long-course chemo/ radiotherapy was the most used approach (79.9\%), followed by short-course radiotherapy \pm chemotherapy (7.6\%). The use of neoadjuvant treatment for cancer of the upper third $(15-11 \mathrm{~cm})$ increased over time $(31.5 \%$ vs $34.5 \%$ vs $38.6 \%, \mathrm{p}=0.0018)$. The complete regression rate slightly increased over time $(15.6 \%$ vs $16 \%$ vs $18.5 \%$; $=0.0093)$; the proportion of patients with involved circumferential resection margins (CRM) went down from $8.2 \%$ to $7.3 \%$ and $5.5 \%(\mathrm{p}=0.0004)$. Neoadjuvant treatment significantly decreased positive CRM in lower third tumors (OR 0.71, 0.59-0.87, Cochrane-Mantel-Haenszel $\mathrm{P}=0.0008$ ). Most ypN0 patients also received adjuvant therapy. In MR-defined stage III patients, preoperative treatment was associated with significantly longer local-recurrence-free survival $(p<0.0001)$, and cancer-specific survival $(\mathrm{p}<0.0001)$. The survival benefit was smaller in upper third cancers. Conclusion: There was an increasing trend and a potential overuse of neoadjuvant treatment in cancer of the upper rectum. Most ypNO patients received postoperative treatment. Involvement of CRM in lower third tumors was reduced after neoadjuvant treatment. Stage III and MRcN + benefited the most.
\end{abstract}

๑ 2020 Elsevier Ltd, BASO The Association for Cancer Surgery, and the European Society of Surgical Oncology. All rights reserved.

\footnotetext{
A preliminary report of this study was accepted as abstract at the 2019 Annual Scientific Meeting of the American Society of Colon and Rectal Surgeons ASCRS, Cleveland, 1-6 June 2019

* Corresponding author. Department of Surgery, University of Valencia, C/Pizarro 5 2-2, 46004, Valencia, Spain

E-mail address: eggranero@telefonica.net (E. García-Granero).

@cirdig_lafe (E. García-Granero)
} 


\section{Introduction}

Neoadjuvant treatment for rectal cancer combined with proper total mesorectal excision (TME) has been shown to increase local control after curative resection. Over the last years, indications as well as treatment modalities have greatly evolved. A significant variation on them can also be observed when comparing different guidelines for the management of rectal cancer [1-3].

The benefits of neoadjuvant treatment come at the cost of several side effects [4-6], which are often underplayed, due to the short-term outcomes reported in most trials [7]. In addition, an excess of noncancer deaths after neoadjuvant treatment has been reported $[7,8]$. This could be important, at a time when there is a trend for an increased use of neoadjuvant treatment for rectal cancer.

The need of assessing and improving the outcomes of rectal cancer treatment, led to the set-up of several multicentric registries and initiatives, aimed at capturing data on patients treated over the last decades. Examples include the Norwegian Registry [9] and the Optimizing Surgical Treatment of Rectal Cancer (OSTRiCh) Consortium in the US [10]. Similarly, the Spanish Association of Surgeons (AEC) [11] started in 2006 a national educational project to implement TME across the country, by means of an online database of patients treated for primary rectal cancer. The registry captured data on neoadjuvant and adjuvant treatment, as well as pathological and survival outcome. This article aims at reporting on the trends of use and oncological results of neoadjuvant treatment for rectal cancer over ten years in the context of a quality-improvement initiative.

\section{Material and methods}

This is a retrospective analysis of a prospective national database. The report complies with the Strengthening the Reporting of Observational Studies in Epidemiology (STROBE) statement [12]. The AEC Registry followed the same principles of the Norwegian Registry [9]. The eventual aims were to improve the quality of treatment incorporating TME and multimodal treatment for patients with rectal cancer nationally.

Between 2006 and 2017, 105 hospitals joined the registry with nearly 19,000 patients. All patients, who underwent surgery with curative intent between 2006 and 2017 were evaluated for inclusion. The analyses were conducted after obtaining Ethical Committee approval.

\section{Inclusion criteria}

Patients were excluded if they did not receive surgery, if surgery was with palliative intent or if it did not involve resection of the tumor, and if they had metastatic disease at presentation.

\section{Definitions}

Neoadjuvant treatment was captured in the database. Data on adjuvant treatment were also collected. Patients were stratified in three timeframes: I) 2006-2009; II) 2010-2013; III) 2014-2017. Local recurrence (LR) was defined as peritoneal, pelvic, or perineal tumor re-growth after curative resection. Distant recurrences were defined as evidence of disease in any other location. Cancer-specific survival (CSS) was defined as death as a consequence of cancer. For overall survival (OS), death for any cause was assessed.

Preoperative assessment was performed by means of CT, MRI, endoscopy, and endorectal ultrasonography, as available. A rigid proctoscopy was used to define tumour height. Definitions and scope of the registry have been previously reported in details [13-15].

\section{Endpoints}

The primary endpoint was the rate of patients that received neoadjuvant treatment.

Secondary endpoints included the type of treatment used, the trends of treatment over time, and likeliness of receiving postoperative treatment.

Sub-analyses correlated neoadjuvant treatment with pathologic regression and rates of circumferential margin (CRM) involvement.

Additional analyses included 3-year CSS, OS, LR-free survival, and disease-free survival (DFS) after neoadjuvant treatment in the timeframes I (2006-2009) and II (2010-2013).

\section{Statistical analysis}

Continuous variables are reported as median (range), categorical variables are reported as number with percentage (\%).

Categorical variables were compared with Fisher's exact test and Chi Square Test for trends as appropriate, whereas continuous variables were compared with Mann-Whitney U and KruskalWallis test.

The Cochrane-Mantel-Haenszel test was used to assess the global risk of CRM involvement and positive resection margins in the different timeframes, stratifying patients according to whether a neoadjuvant therapy was used or not [16]. Results are reported as Odds Ratio (OR) with $95 \%$ confidence intervals (95\%CI). OR $>1$ is associated with increased risk.

Binomial logistic regression analyses were run to identify factors associated with neoadjuvant and adjuvant treatment. Only patients that underwent preoperative MRI were included in the regression models, on condition that adequate quantity and quality of information was available. The variables included in the regression for neoadjuvant treatment included sphincter complex status, T stage at MRI (MRcT) and N stage at MRI (MRcN), gender, status of the mesorectal fascia (MRF), tumor height, age, and treatment timeframe. In the regression for adjuvant treatment, pathologic outcomes were also included along with intraoperative perforation, complications, and preoperative treatment.

Kaplan-Meier survival curves were generated to assess survival, and LogRank test was used for comparisons. Cox test was used to estimate the Hazard Ratio (HR). Sensitivity analyses included survival in MRcT3-4 patients and radiological Stage III patients. Subanalyses according to MRcN and cancer height were performed. Only patients with available data on preoperative MRI scan were included.

The statistical Package for Social Sciences (SPSS version 24.0.0; IBM SPSS statistics, IBM Corporation, Armonk, NY) was used for the analyses. $\mathrm{P}$ values $<0.05$ were considered statistically significant.

\section{Results}

Overall, data on 18,782 patients were uploaded on the Registry. After removing 954 patients that did not receive surgery or for whom data were not available, those who underwent emergency surgery, surgery with palliative intent, surgery without resection, pelvic exenteration, local excision, proctocolectomy, transanal TME, and patients with Stage IV disease, a total of 14,391 patients fit in 
inclusion criteria. Characteristics of patients are summarized in Table 1.

\section{Type of neoadjuvant treatment}

A total of 8871 (61.6\%) patients received neoadjuvant treatment. This consisted of long course radiation therapy (RT) or chemoradiation therapy (CRT) in 7377 (79.9\%), short course RT with or without chemotherapy in 674 (7.6\%), chemotherapy followed by RT in 600 (6.8\%), chemotherapy alone in 93 (1\%), and other modalities in 126 (1.4\%). Preoperative assessment included MRI in 94.2\% of patients that received neoadjuvant treatment.

\section{Trends of neoadjuvant treatment over time}

Patients receiving neoadjuvant treatment went slightly up from $58.2 \%$ during the first timeframe to $62.5 \%$ and $62.6 \%$ in the more recent timeframes (Supplementary Fig. 1A). Long course RT alone was less frequently advocated over time ( $4.5 \%$ vs $3.1 \%$ vs $2.8 \%$, $\mathrm{p}=0.0051)$. CRT decreased during the second timeframe and increased during the third one ( $88.9 \%$ vs $76.2 \%$ vs $80.6 \%$ ), and always represented the most used modality. (Supplementary Fig. 2).

In terms of tumor height, the rate of patients receiving preoperative therapy for cancer of the upper third $(15-11 \mathrm{~cm})$ increased over time, being $31.5 \%, 34.5 \%$, and $38.6 \%$ in period I, II and III $(\mathrm{p}=0.0018)$ (Fig. 1). Radiological stage I tumors treated with neoadjuvant treatment decreased over time (26\% vs $10.1 \%$ vs $3.3 \%$, $\mathrm{p}<0.0001)$, whereas the rates of stage II remained stable $(48.2 \% \mathrm{vs}$ $52.2 \%$ vs $48.7 \%, \mathrm{p}=0.89$ ). Stage III patients receiving neoadjuvant treatment significantly increased over time $(73.1 \%$ vs $80.6 \%$ vs $82.5 \%, \mathrm{p}<0.0001)$. There was an increasing use of pre-treatment MRI $(88.1 \%$ vs $95.2 \%$ vs $96.3 \%, \mathrm{p}<0.0001)$. More advanced MRcT and MRcN were observed in more recent timeframes.

\section{Pathological outcome of neoadjuvant treatment}

Complete pathological regression was achieved in $15.7 \%$ of patients, whereas $6.6 \%$ had no response. We observed an increasing trend over the three timeframes (15.6\% vs $16 \%$ vs $18.5 \%$; $\mathrm{p}=0.0093)$. $\mathrm{pNx}$ and $\mathrm{pN0}$ were increasingly observed during time compared with pN1-2 (70.6\% vs $71.9 \%$ vs $72.9 \%, \mathrm{p}=0.009$ ).

The involved CRM after neoadjuvant treatment decreased over time $(8.2 \%$ vs $7.3 \%$ vs $5.5 \%, \mathrm{p}=0.0004)$. The same occurred in patients who did not receive preoperative treatment ( $10.7 \%$ vs $8.5 \%$ vs $4.6 \%, \mathrm{p}<0.0001)$. In patients with cancer of the distal rectum, the risk of + ve CRM was significantly reduced by neoadjuvant treatment over the three timeframes (OR 0.71, 0.59-0.87, CochranMantel-Haenszel $\mathrm{P}=0.0008$ ). However, no significant differences were observed comparing all patients who received vs those who did not receive neoadjuvant treatment in the three different timeframes (OR 0.88, 0.64-1.20, Cochrane-Mantel-Haenszel $\mathrm{P}=0.42$ ).

The median number of nodes retrieved on the specimen was lower after neoadjuvant treatment compared with no neoadjuvant treatment (12 [0-100] vs 15 [0-150], p < 0.0001), with no significant differences in positive node ratio. Trends were stable over time (Table 1).

\section{Postoperative treatment}

Up to $76.4 \%$ of patients that received neoadjuvant treatment, also received postoperative treatment (Supplementary Fig. 1B). Most ypN0 patients also received adjuvant therapy in all the timeframes (72.1\% vs $73 \%$ vs $69.7 \%, \mathrm{p}=0.262$ ).
Factors associated with indication to neoadjuvant and adjuvant treatment

Factors associated with the use of neoadjuvant treatment included threatened MRF (OR 1.285, 95\%CI 1.038-1.592, $\mathrm{p}=0.022$ ); tumor location, being 5 times higher for tumors of the lower third (OR 5.222, 95\%CI 4.234-6.440, p $<0.0001$, advanced MRcT and MRcN stage. Female gender and advanced age ( $>65$ year-of-age) were associated with lower use of neoadjuvant treatment (Table 2).

Factors associated with the use of adjuvant treatment included preoperative treatment (OR 6.316, 95\%CI 5.705-6.992, $\mathrm{p}<0.0001$ ), perioperative complications (OR 1.694, 95\%CI 1.544-1.858, $\mathrm{p}<0.0001$ ), as well as pT and pN stage. Again, female gender and age $>65$ years were associated with lower use of adjuvant treatment, along with cancers of the middle and lower rectum (Table 3 ).

\section{Disease-free survival, cancer-specific and overall survival after neoadjuvant treatment over time}

Overall, OS was significantly improved in timeframes 2006-2009 and 2010-2013 either with or without preoperative treatment $(\mathrm{p}<0.0001)$, whereas CSS survival significantly improved in patients who did not receive neoadjuvant treatment (Table 4). LR and DFS did not differ.

When considering tumor height, the benefits of neoadjuvant treatment in terms of LR tended to be more evident in patients with cancer of the lower third ( $\mathrm{p}=0.144)$. CSS and OS were improved after neoadjuvant treatment, but patients with high rectal cancer had little benefit $(\mathrm{p}<0.0001$ ) (Suppl. Figure 3 and Suppl. Figure 4).

In patients with radiological stage III rectal cancer, preoperative treatment was associated with significantly longer LR free survival $(\mathrm{p}<0.0001)$, CSS $(\mathrm{p}<0.0001)$ and OS ( $\mathrm{p}<0.0001)$ in both timeframes. These differences are particularly relevant in MRcN2 patients. A trend towards an improved DFS was observed with neoadjuvant treatment in Stage III and $\mathrm{MRcN}+$ ve patients (Suppl. Figure 3).

\section{Discussion}

In this national registry, despite a wider use of MRI as staging tool, which currently defines the risk factors for a more selective approach, preoperative therapy has been consistently used and slightly increased over time. Patients with advanced locoregional stages such as a deep penetration into the mesorectal space, threatened or involved MRF, extramural vascular invasion or extensive nodal involvement are in general considered at risk and neoadjuvant treatment is recommended. After 2010, approximately $62.5 \%$ of all patients underwent preoperative treatment. This potential overuse was particularly detected in patients with upper rectal cancer, where the use of preoperative treatment can be more contentious [17]. The CSS benefit was more apparent in cancers of the lower third, whereas omitting preoperative treatment would have not affected much the survival of those with upper third cancers (Fig. 2). Neoadjuvant treatment has significantly improved the outcome in terms of local disease control. These benefits must be weighed against undesired side effects [6]. The EURECCA consortium compared the rates of preoperative treatment for rectal cancer among five different European countries between 2008 and 2009 , and found significant variation, ranging between $28 \%$ and $86 \%$ [18]. The highest rates were found in the Nederland. Following on this report, the Dutch Surgical Colorectal Cancer Audit Group performed a critical appraisal on the use of RT in Nederland [19]. After publication of the revised national guidelines in 2014, the use of RT decreased by $32.8 \%, 43.5 \%$ and $31.6 \%$ for cT1N0, cT2N0 and cT3N0 stage, respectively [19]. In the present series, we observed an 
Table 1

Demographic and multimodal therapy details for patients treated in three timeframes.

\begin{tabular}{|c|c|c|c|c|c|}
\hline Variable & $2006-2009(n=2923)$ & \multicolumn{2}{|c|}{$2010-2013(n=7370)$} & $2014-2017(n=4098)$ & P value \\
\hline Age, years & $69(23-95)$ & \multicolumn{2}{|l|}{$69(22-100)$} & $68(21-94)$ & 0.646 \\
\hline Female gender & $985(33.7)$ & \multirow{2}{*}{\multicolumn{2}{|c|}{$2505(34)$}} & $1465(35.7)$ & 0.06 \\
\hline \multicolumn{3}{|l|}{ ASA score: } & & & \multirow[t]{5}{*}{0.0001} \\
\hline$-I$ & $171(5.9)$ & $442(6.0)$ & 277 & & \\
\hline - II & $1601(54.8)$ & 3904 (53) & 2079 & & \\
\hline - III & $1057(36.2)$ & $2756(37.4)$ & 1641 & & \\
\hline - IV & $94(3.2)$ & $268(3.6)$ & 101 & & \\
\hline \multicolumn{5}{|l|}{ Tumor height } & \multirow{4}{*}{0.018} \\
\hline$-11-15 \mathrm{~cm}$ & $718(24.6)$ & $1749(23.7)$ & 1035 & & \\
\hline$-7-10 \mathrm{~cm}$ & $1051(36)$ & $2838(38.5)$ & 1583 & & \\
\hline$-0-6 \mathrm{~cm}$ & $1154(39.5)$ & $2783(37.8)$ & 1480 & & \\
\hline \multicolumn{5}{|l|}{ MRcT: } & \multirow[t]{7}{*}{$<0.0001$ * } \\
\hline - T0 & $22(0.8)$ & $43(0.6)$ & $36(0$ & & \\
\hline - T1 & $288(9.9)$ & $125(1.7)$ & $59(1$ & & \\
\hline$-\mathrm{T} 2$ & 1107 (37.9) & $1354(18.4)$ & 803 & & \\
\hline - T3 & $827(28.3)$ & $4136(56.1)$ & 2333 & & \\
\hline$-\mathrm{T} 4$ & $120(4.1)$ & $912(12.4)$ & 497 & & \\
\hline - Missing & $559(19.1)$ & $800(10.9)$ & 370 & & \\
\hline \multicolumn{5}{|l|}{ MRcN: } & \multirow[t]{5}{*}{ 0.003* } \\
\hline - NO & $803(27.5)$ & $2161(29.3)$ & 1158 & & \\
\hline$-N 1$ & $940(32.2)$ & $2491(33.8)$ & 1420 & & \\
\hline$-\mathrm{N} 2$ & $621(21.2)$ & $1918(26)$ & 1150 & & \\
\hline - Missing & $559(19.1)$ & 800 (10.9) & 370 & & \\
\hline \multicolumn{5}{|l|}{ Radiological Stage: } & $<0.0001 *$ \\
\hline$-I$ & $617(21.1)$ & $1070(14.5)$ & 514 & & \\
\hline- II & $398(13.6)$ & $1288(17.5)$ & 620 & & \\
\hline - III & $1786(61.1)$ & $4658(63.2)$ & 2663 & & \\
\hline - not formally stated & $132(4.2)$ & $354(4.9)$ & 301 & & \\
\hline Neoadjuvant treatment & $1701(58.2)$ & $4603(62.5)$ & 2567 & & $<0.0001$ \\
\hline - Long course RT & $76(4.5)$ & $141(3.1)$ & $72(2$ & & \\
\hline - Long course CRT & $1512(88.9)$ & $3509(76.2)$ & & & \\
\hline - ChT & $14(0.8)$ & $60(1.3)$ & $19(0$ & & \\
\hline - Short Course RT \pm ChT & $80(4.7)$ & $434(9.4)$ & 160( & & \\
\hline - ChT followed by RT & $19(1.1)$ & $443(9.6)$ & 138( & & \\
\hline - other & $-(-)$ & $16(0.3)$ & 111( & & \\
\hline Perforation & $131(4.5)$ & $298(4.0)$ & 185( & & 0.053 \\
\hline Adjuvant treatment & $1788(61.2)$ & $4545(61.7)$ & 2087 & & $<0.0001$ \\
\hline ypT: & in 1701 patients & in 4603 patients & in 25 & tients & $<0.0001 *$ \\
\hline$-T x$ & $52(3.1)$ & $95(2.1)$ & $23(0$ & & \\
\hline - T0 & $216(12.7)$ & $619(13.4)$ & 426( & & \\
\hline - Tis & $17(1.0)$ & $57(1.2)$ & $30(1$ & & \\
\hline$-\mathrm{T} 1$ & $108(6.3)$ & $237(5.1)$ & 157( & & \\
\hline$-\mathrm{T} 2$ & $444(26.1)$ & $1255(27.3)$ & 697( & & \\
\hline - T3 a,b & $510(30)$ & $1554(33.8)$ & 873 & & \\
\hline$-\mathrm{T} 3 \mathrm{c}, \mathrm{d}$ & $293(17.2)$ & $528(11.5)$ & 201( & & \\
\hline$-\mathrm{T} 4 \mathrm{a}$ & $39(2.3)$ & $136(3.0)$ & $68(2$ & & \\
\hline$-\mathrm{T} 4 \mathrm{~b}$ & $22(1.3)$ & $106(2.3)$ & $39(1$ & & \\
\hline - Missing & $0(0)$ & $16(0.3)$ & $53(2$ & & \\
\hline ypN: & in 1701 patients & in 4603 patients & in 25 & tients & 0.008* \\
\hline$-N x$ & $588(34.6)$ & $1594(34.6)$ & 840 & & \\
\hline - NO & $612(36.0)$ & $1705(37)$ & 995( & & \\
\hline$-\mathrm{N} 1$ & $342(20.1)$ & $867(18.8)$ & 505( & & \\
\hline$-\mathrm{N} 2$ & $158(9.3)$ & $421(9.1)$ & 174 & & \\
\hline - Missing & $0(0)$ & $16(0.3)$ & $53(2$ & & \\
\hline Variable & & $2006-2009(n=2923)$ & $2010-2013(n=7370)$ & $2014-2017(n=4098)$ & P value \\
\hline Number of isolated lymph & neoadjuvant treatment & $12(0-58)$ & $12(0-91)$ & $12(0-107)$ & 0.791 \\
\hline Distal margin affected afte & t treatment ${ }^{\mathrm{a}}$ & $11(0.6)$ & $33(0.7)$ & $17(0.7)$ & 0.953 \\
\hline CRM affected after neoadj & ent $^{\mathrm{b}}$ & $140(8.2)$ & $336(7.3)$ & $139(5.5)$ & 0.0004 \\
\hline Quality of the mesorectun & juvant treatment $\mathrm{t}^{\mathrm{c}}$ & & & & 0.308 \\
\hline - Complete & & $1348(80)$ & 3576 (79.8) & $2026(80.6)$ & \\
\hline - Nearly complete & & $237(14.1)$ & $583(13)$ & $317(12.6)$ & \\
\hline - Incomplete & & $99(5.9)$ & $321(7.2)$ & $171(6.8)$ & \\
\hline
\end{tabular}

Data are expressed as number of patients (\%) or median (range).

*only including available information.

ASA: American Society of Anesthesiologists.

ChT Chemotherapy.

CRT chemoradiation therapy.

MR Magnetic Resonance.

$\mathrm{RT}$ radiation therapy.

a 5/1701 missing in 2006-2009; 44/4603 missing in 2010-2013; 53/2567 missing in 2014-2017.

b $1 / 1701$ missing in 2006-2009; 19/4603 missing in 2010-2013; 53/2567 missing in 2014-2017.

c $17 / 1701$ missing in 2006-2009; $123 / 4603$ missing in 2010-2013; 53/2567 missing in 2014-2017. 


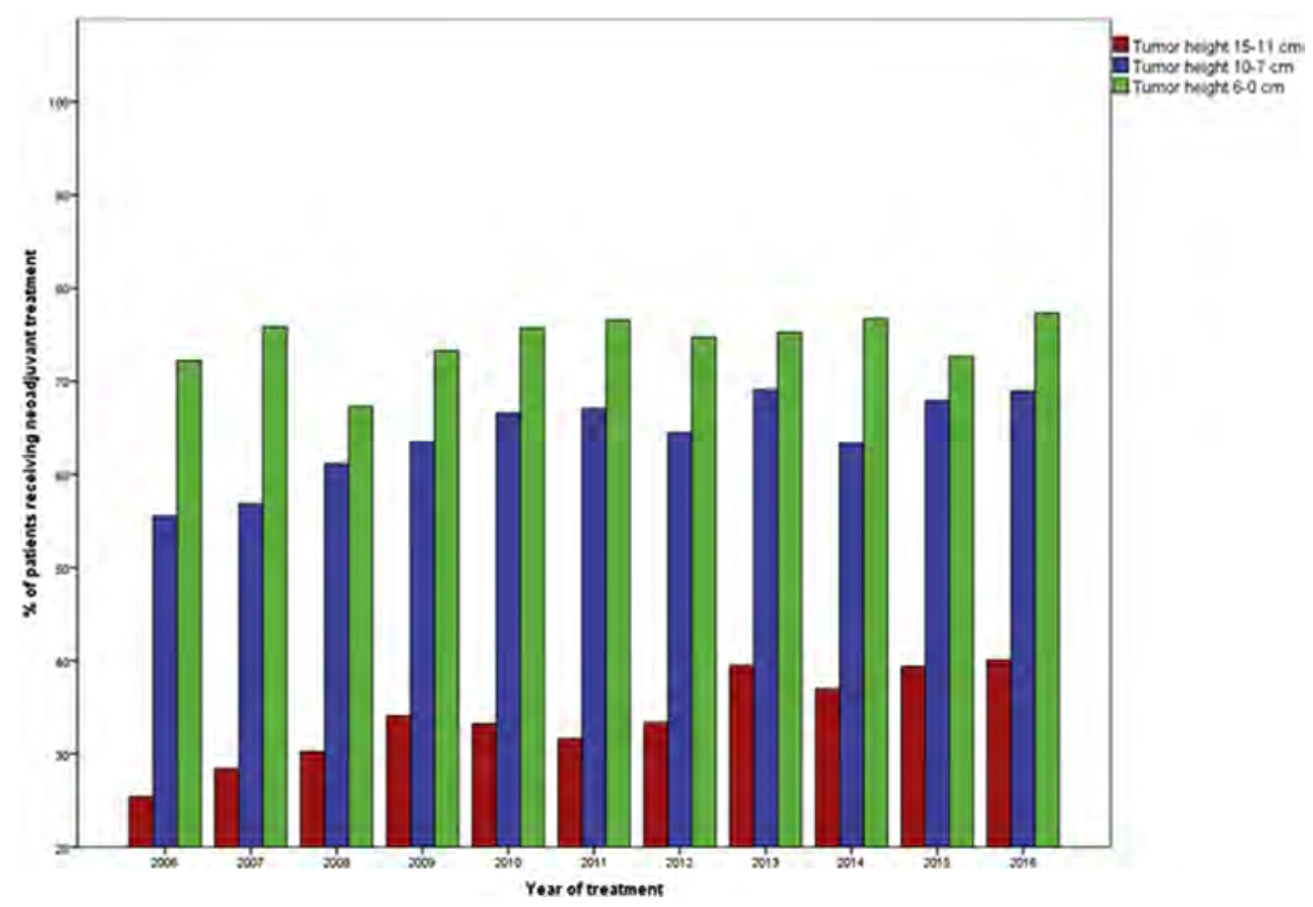

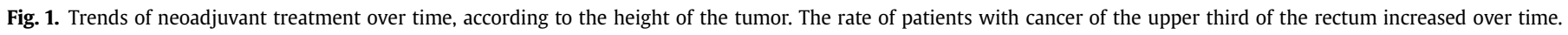

Table 2

Multivariate regression for factors associated with preoperative treatment (neoadjuvant treatment).

\begin{tabular}{lllll}
\hline & OR & $95 \%$ CI & & p-value \\
\hline Gender: & & & & $<\mathbf{0 . 0 0 0 1}$ \\
- Male & 1 & - & - & \\
- Female & 0.758 & 0.648 & 0.885 & \\
Age: & & & & $<\mathbf{0 . 0 0 0 1}$ \\
- <65 year-of-age & 1 & - & - & \\
- $\geq$ 65 year-of-age & 0.582 & 0.498 & 0.679 & \\
Mesorectal fascia threatened & 1.285 & 1.038 & 1.592 & $\mathbf{0 . 0 2 2}$ \\
Sphincter complex involved & 1.138 & 0.766 & 1.691 & 0.522 \\
Tumor height: & & & & $<\mathbf{0 . 0 0 0 1}$ \\
- 15-11 cm & 1 & - & - & \\
- 7-10 cm & 3.304 & 2.750 & 3.970 & \\
- 0-6 cm & 5.222 & 4.234 & 6.440 & \\
MRcT stage: & & & & $\mathbf{0 . 0 0 0 1}$ \\
- cT1 & 1 & - & - & \\
- cT2 & 2.287 & 1.503 & 3.482 & \\
- cT3 & 4.826 & 3.141 & 7.415 & \\
- cT4 & 7.951 & 3.844 & 16.443 & \\
MRcN stage: & & & & $\mathbf{0 . 0 0 0 1}$ \\
- cN0 & 1 & - & - & \\
- cN1 & 5.250 & 4.430 & 6.222 & \\
- cN2 & 8.920 & 7.249 & 10.977 & \\
Timeframe of treatment & & & & 0.247 \\
- 2006-2009 & 1 & - & - & \\
- 2010-2013 & 0.882 & 0.714 & 1.090 & \\
- 2014-2017 & 1.010 & 0.774 & 1.319 & \\
\hline
\end{tabular}

MR: magnetic resonance OR: Odds Ratio; 95\%CI 95\% confidence intervals.

OR $>1$ associated with increased used of neoadjuvant treatment; statistically significant values bold.

increasing trend, reaching $62,5 \%$ in the last period, which warrants further investigation.

Discrepancies can be observed among the available guidelines concerning the indications to preoperative treatment [1]. In US, the trend is to offer widely neoadjuvant treatment based on MRcT and MRcN. Guidelines from US recommends neoadjuvant treatment in all patients with any CT3 rectal cancer (including N0),
Table 3

Multivariate regression for factors associated with postoperative treatment (adjuvant treatment)

\begin{tabular}{|c|c|c|c|c|}
\hline & OR & $95 \% \mathrm{CI}$ & & p-value \\
\hline Gender: & & & & 0.025 \\
\hline - Male & 1 & - & - & \\
\hline - Female & 0.897 & 0.816 & 0.986 & \\
\hline Age: & & & & $<0.0001$ \\
\hline$-<65$ year-of-age & 1 & - & - & \\
\hline$-\geq 65$ year-of-age & 0.393 & 0.357 & 0.432 & \\
\hline Intraoperative perforation & 1.011 & 0.790 & 1.293 & 0.932 \\
\hline Tumor height: & & & & 0.070 \\
\hline$-15-11 \mathrm{~cm}$ & 1 & - & - & \\
\hline$-7-10 \mathrm{~cm}$ & 0.874 & 0.773 & 0.989 & \\
\hline$-0-6 \mathrm{~cm}$ & 0.874 & 0.770 & 0.992 & \\
\hline Lymph nodes on specimen: & & & & 0.832 \\
\hline$-\geq 12$ & 1 & - & - & \\
\hline$-<12$ & 1.022 & 0.836 & 1.249 & \\
\hline Involved circumferential margin & 1.125 & 0.919 & 1.377 & 0.255 \\
\hline Involved distal margin & 0.943 & 0.564 & 1.578 & 0.823 \\
\hline pT stage: & & & & $<0.0001$ \\
\hline- pTx & 1 & - & - & \\
\hline - pT0 & 1.147 & 0.761 & 1.728 & \\
\hline - pTis & 0.467 & 0.278 & 0.785 & \\
\hline - pT1 & 0.579 & 0.382 & 0.879 & \\
\hline - pT2 & 0.803 & 0.542 & 1.189 & \\
\hline - pT3 a.b & 1.359 & 0.916 & 2.017 & \\
\hline - pT3 c.d & 1.424 & 0.942 & 2.152 & \\
\hline - pT4a & 2.013 & 1.247 & 3.251 & \\
\hline - pT4 b & 2.298 & 1.345 & 3.928 & \\
\hline pN stage: & & & & $<\mathbf{0 . 0 0 0 1}$ \\
\hline$-\mathrm{pNx}$ & 1 & - & - & \\
\hline- pNO & 0.741 & 0.592 & 0.928 & \\
\hline$-\mathrm{pN} 1$ & 2.748 & 2.262 & 3.339 & \\
\hline$-\mathrm{pN} 2$ & 2.543 & 2.006 & 3.225 & \\
\hline Timeframe of treatment & & & & 0.744 \\
\hline$-2006-2009$ & 1 & - & - & \\
\hline$-2010-2013$ & 0.971 & 0.862 & 1.094 & \\
\hline$-2014-2017$ & 0.949 & 0.830 & 1.085 & \\
\hline
\end{tabular}

OR: Odds Ratio; 95\%CI 95\% confidence intervals.

OR $>1$ associated with increased used of adjuvant treatment; statistically significant values bold. 
Table 4

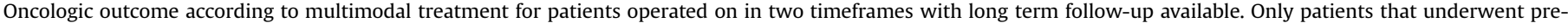
operative MRI assessment were included.

\begin{tabular}{|c|c|c|c|c|}
\hline Variable & 2006-2009 & 2010-2013 & OR $(95 \% \mathrm{CI})$ & $P$ value \\
\hline \multicolumn{5}{|l|}{ Local Recurrence } \\
\hline - No neoadjuvant treatment & $33 / 793(4.16)$ & $79 / 2034(3.88)$ & $1.08(0.71-1.63)$ & 0.73 \\
\hline - Neoadjuvant treatment & $64 / 1407(4.54)$ & $145 / 4099(3.54)$ & $1.29(0.96-1.75)$ & 0.09 \\
\hline \multicolumn{5}{|l|}{ Distant recurrence } \\
\hline - No neoadjuvant treatment & $106 / 793(13.37)$ & $227 / 2034(11.16)$ & $1.23(0.96-1.57)$ & 0.10 \\
\hline -Neoadjuvant treatment & $197 / 1407(14)$ & $588 / 4099(14.34)$ & $0.97(0.82-1.16)$ & 0.75 \\
\hline \multicolumn{5}{|l|}{ Death for cancer } \\
\hline -No neoadjuvant treatment & $67 / 793(8.45)$ & $126 / 2034(6.2)$ & $1.39(1.03-1.90)$ & 0.03 \\
\hline - Neoadjuvant treatment & $75 / 1407(5.33)$ & $169 / 4099(4.12)$ & $1.31(0.99-1.73)$ & 0.06 \\
\hline \multicolumn{5}{|l|}{ Death for any cause } \\
\hline - No neoadjuvant treatment & $179 / 793(22.57)$ & $288 / 2034(14.16)$ & $1.77(1.44-2.18)$ & $<0.0001$ \\
\hline - Neoadjuvant treatment & $223 / 1407(15.85)$ & $475 / 4099$ (11.59) & $1.44(1.21-1.71)$ & $<0.0001$ \\
\hline
\end{tabular}

Data are expressed as number of patients (\%). OR>1 favors the time frame 2010-2013 (increased risk for the time frame 2006-2009).

MRI Magnetic Resonance Imaging.

OR Odds Ratio.

95\%CI 95\% confidence intervals.
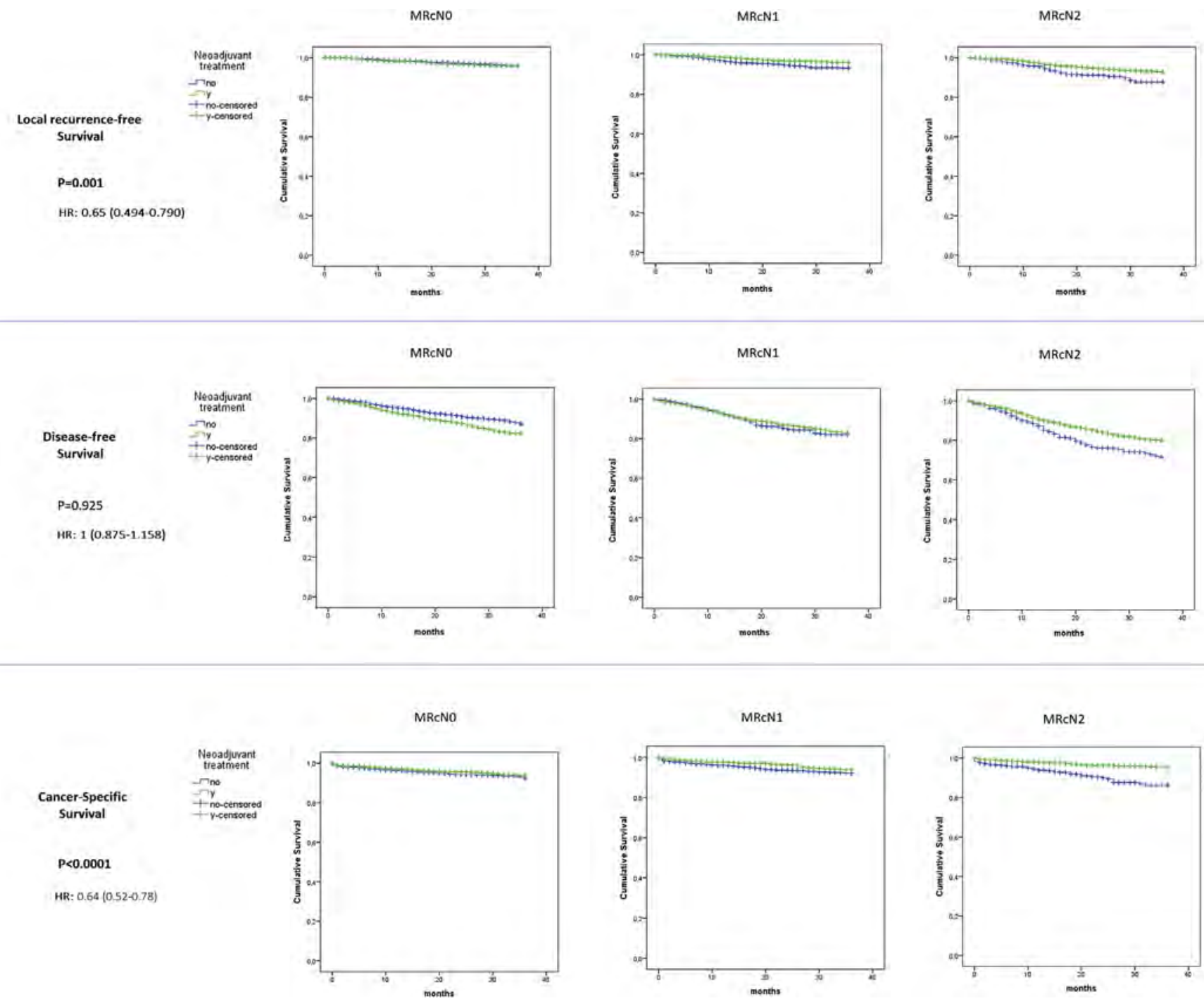

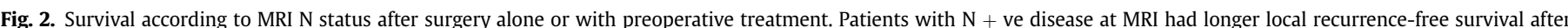

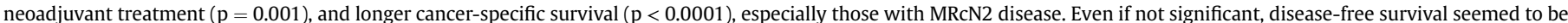
longer after preoperative treatment, but this was only observed in MRcN2 patients, suggesting a potential detrimental effect in $\mathrm{N}$-ve individuals. 
independently of the mesorectal spread of the tumor front [2]. However, this is not the case in current European guidelines, in which selected cT3a/b cancers with minimal penetration into the mesorectal fat are considered amenable for surgical resection without preoperative treatment [1-3], even with suspicious nodes in the mesorectum $[3,20,21]$. Very recently, the so-called totallyneoadjuvant treatment (TNT) has been described, consisting of CRT followed by consolidation chemotherapy [22]. Although TNT has been associated with reasonable mid-term rates of rectal sparing in T3/T4 N0/N1 resectable cancers of the distal rectum, the role of such treatment should be further elucidated [22,23].

The presence of an involved or threatened MRF is the strongest predictor of LR after curative surgery for rectal cancer, and it should therefore be used to select patients for neoadjuvant treatment $[20,21]$. The most relevant finding of this study is the significant decrease in +ve CRM over time, ranging from $8.2 \%$ in the first timeframe to $7.3 \%$ in the second period and $5.5 \%$ in the last one. This positive outcome could be a key achievement of this national program. On the other hand, the assessment of surgical quality was based upon the surgical plane defined by the pathologist in the resected specimen, as mesorectal around $80 \%$ across the three timeframes. Patients who benefited more from preoperative treatment in terms of R0 resections, were those with cancers located at the lower rectum. Patients with clinical stage III, particularly those with $\mathrm{N} 2$ lymph nodal involvement, were those to benefit the most from neoadjuvant treatment in terms of LR, DFS, CSS and OS. In patients with upper third rectal cancer, the impact of neoadjuvant treatment on CSS and OS survival was smaller.

The present study found that neoadjuvant treatment was particularly beneficial for MR-defined stage-III patients, whereas this effect was questionable or less obvious when assessing MRcT and in MRcN0 stage alone. Recently, the QuickSilver trial proposed a combination of MRI-based features to identify patients suitable for surgery without CRT [24]. The MERCURY II study also recommended MRI assessment of low rectal cancers to reduce overtreatment and postoperative morbidity [25].

\section{Limitations}

This national study has several limitations, mostly derived from its retrospective analysis. Firstly, data were uploaded on a voluntary basis. The agents and dose used for treatment were not recorded. No data were available concerning the time between the completion of preoperative treatment and surgery. By spreading over 10 years, the herein reported analyses might have been influenced by the evolving treatment modalities over time. Lastly, long term toxicity and specific adverse events of preoperative treatment were not systematically recorded.

One of the main strengths of the study is the involvement of many multidisciplinary teams in different centers across the country in a step-wise educational program on proper TME surgery, sharing common criteria for radiological and pathology staging as well as neoadjuvant treatment. The increased performances in terms of both pathologic and survival outcomes confirmed the benefits of establishing the registry [11,13-15]. Some policies need further investigation, especially the management of patients with cancers of the upper rectum and those with early stages. Additional MRI-based factors and biomolecular markers [24,26] are likely to provide more information on the open issues on multimodal treatment for rectal cancer, and allow the development of a complete prognostic index for treatment individualization [7].

\section{COLLABORATORS}

Rectal Cancer (Viking) Project
Raúl Adell Carceller (Hospital de Vinaroz), Juan Guillermo Ais Conde (Hospital de Segovia), Evelio Alonso Alonso (Complejo Asistencial de Burgos), Antonio Amaya Cortijo (Hospital San Juan de Dios del Aljarafe de Sevilla), Antonio Arroyo Sebastian (Hospital General Universitario de Elche), Pedro Barra Baños (Hospital General Reina Sofía de Murcia), Ricard Batlle Solé (Hospital de Santa María de Lleida), Juan C. Bernal Sprekelsen (Hospital de Requena), Sebastiano Biondo (Hospital Universitari de Bellvitge), Francisco J. Blanco Gonzalez (Hospital La Ribera, Alzira), Santiago Blanco (Hospital de Reus), J. Bollo (Hospital Universitari de la Santa Creu i Sant Pau de Barcelona), Nieves Cáceres Alvarado (Complejo Hospitalario de Vigo Xeral + Meixoeiro), Ignasi Camps Ausas (Hospital Universitari Germans Trias i Pujol de Badalona), Ramon Cantero Cid (Hospital Infanta Sofía de Madrid), José Antonio Carmona Saez (Hospital Nuestra Señora de Sonsoles de Ávila), Enrique Casal Nuñez (Complejo Hospitalario de Vigo Xeral + Meixoeiro), Luis Cristobal Capitán Morales (Hospital Virgen Macarena de Sevilla), Guillermo Carreño Villarreal (Hospital de Cabueñes de Gijón), Jesús Cifuentes Tebar (Hospital General de Albacete), Miguel Á. Ciga Lozano (Hospital Virgen del Camino-Complejo Hospitalario de Navarra), Antonio Codina Cazador (Hospital Universitari de Girona Dr. Josep Trueta), Juan de Dios Franco Osorio (Hospital General de Jerez), María de la Vega Olías (Hospital Puerto Real de Cádiz), Mario de Miguel Velasco (Hospital Virgen del Camino-Complejo Hospitalario de Navarra), Sergio Rodrigo del Valle (Hospital General Rafael Mendez de Murcia), José G. Díaz Mejías (Hospital Nuestra Señora de la Candelaria de Tenerife), José M. Díaz Pavón (Hospital Virgen del Rocío de Sevilla), Javier Die Trill (Hospital Universitario Ramón y Cajal de Madrid), José L. Dominguez Tristancho (Hospital de Mérida), Paula Dujovne Lindenbaum (Hospital Universitario Fundación Alcorcón), José Errasti Alustiza (Hospital Txagorritxu de Vitoria), Alejandro Espí Macias (Hospital Clínico Universitario de Valencia), Eloy Espín Basany (Hospital Universitari Vall d'Hebron de Barcelona), Rafael Estévan Estévan (Instituto Valenciano de Oncología IVO), Alfredo M. Estevez Diz (Hospital Policlínico Povisa de Vigo), Luis Flores (Hospital Clínico y Provincial de Barcelona), Domenico Fraccalvieri (Hospital Universitari de Bellvitge), Alessandro Garcea (Hospital Torrevieja Salud UTE), Mauricio García Alonso (Hospital Clínico San Carlos de Madrid), Miguel Garcia Botella (Hospital General Universitario de Valencia), Maria José García Coret (Hospital General Universitario de Valencia), Alfonso García Fadrique (Instituto Valenciano de Oncología IVO), José M. García García (Hospital de Cruces), Jacinto García García (Complejo Asistencial de Salamanca), Eduardo García-Granero (Hospital Universitario y Politécnico La Fe de Valencia), Jesús Á. Garijo Alvarez (Hospital de Torrejón), José Gomez Barbadillo (Hospital Universitario Reina Sofía de Córdoba), Fernando Gris (Hospital Universitari Joan XXIII de Tarragona), Verónica Gumbau (Hospital General Universitario de Valencia), Javier Gutierrez (Complejo Hospitalario de Jaén), Pilar Hernandez Casanovas (Hospital Universitari de la Santa Creu i Sant Pau de Barcelona), Daniel Huerga Alvarez (Hospital Universitario de Fuenlabrada), Ana M. Huidobro Piriz (Complejo Hospitalario de Palencia), Francisco Javier Jimenez Miramón (Hospital Universitario de Getafe), Ana Lage Laredo (Hospital Nuestra Señora del Rosell), Alberto Lamiquiz Vallejo (Hospital de Cruces), Félix Lluis Casajuana (Hospital General Universitario de Alicante), Manuel López Lara (Hospital Espíritu Santo de Santa Coloma de Gramanet), Juan A. Lujan Mompean (Hospital Virgen de la Arrixaca), María Victoria Maestre (Hospital Virgen del Rocío de Sevilla), Eva Martí Martínez (Hospital Dr. Peset de Valencia), M. Martinez (Hospital Universitari de la Santa Creu i Sant Pau de Barcelona), Javier Martinez Alegre (Hospital Infanta Sofía de Madrid), Gabriel Martínez Gallego (Complejo Hospitalario de Jaén), Roberto Martinez Pardavila (Onkologika de San Sebastian), Olga Maseda Díaz (Hospital Xeral de Lugo), Mónica Millan Schedling 
(Hospital Universitari Joan XXIII de Tarragona), Benito Mirón (Hospital Clínico Universitario San Cecilio de Granada), José Monzón Abad (Hospital Miguel Servet de Zaragoza), José A. Múgica Martinera (Hospital Donostia), Francisco Olivet Pujol (Hospital Universitari de Girona Dr. Josep Trueta), Mónica Orelogio Orozco (Hospital General Juan Ramón Jimenez de Huelva), Luis Ortiz de Zarate (Consorci Sanitari Integral - Hospital General de L'Hospitalet y Hospital Moisés Broggi), Rosana Palasí Gimenez (Hospital Universitario y Politécnico La Fe de Valencia), Natividad Palencia García (Hospital de Henares, Coslada), Pablo Palma Carazo (Hospital Universitario Virgen de las Nieves), Alberto Parajo Calvo (Complejo Hospitalario de Ourense), Jesús Paredes Cotore (Hospital Clínico Universitario de Santiago de Compostela), Carlos Pastor Idoate (Fundación Jimenez Díaz), Miguel Pera Roman (Hospital del Mar de Barcelona), Francisco Pérez Benítez (Hospital Clínico Universitario San Cecilio de Granada), José A. Pérez García (Hospital Virgen del Puerto de Plasencia), Marta Piñol Pascual (Hospital Universitari Germans Trias i Pujol de Badalona), Isabel Prieto Nieto (Hospital Universitario La Paz de Madrid), Ricardo Rada Morgades (Hospital General Juan Ramón Jimenez de Huelva), Mónica Reig Pérez (Hospital San Juan de Dios del Aljarafe de Sevilla), Ángel Reina Duarte (Hospital Torrecárdenas de Almería), Didac Ribé Serrat (Hospital General de Granollers), Xavier Rodamilans (Hospital de Santa María de Lleida), María D. Ruiz Carmona (Hospital de Sagunto), Marcos Rodriguez Martin (Hospital Gregorio Marañón de Madrid), Francisco Romero Aceituno (Hospital San Pedro de Alcántara de Cáceres), Jesús Salas Martínez (Complejo Hospitalario de Badajoz), Ginés Sánchez de la Villa (Hospital General Rafael Mendez de Murcia), Inmaculada Segura Jimenez (Hospital Universitario Virgen de las Nieves), José Enrique Sierra Grañon (Hospital Universitario Arnau de Vilanova de Lleida), Amparo Solana Bueno (Hospital de Manises), Albert Sueiras Gil (Hospital de Viladecans), Teresa Torres Sanchez (Hospital Dr. Peset de Valencia), Natalia Uribe Quintana (Hospital Arnau de Vilanova de Valencia), Javier Valdés Hernández (Hospital Virgen Macarena de Sevilla), Fancesc Vallribera (Hospital Universitari Vall d'Hebron de Barcelona), Vicent Viciano Pascual (Hospital Lluis Alcanyis de Xàtiva).

\section{CRediT author statement}

Gianluca Pellino: Conceptualization, Methodology, Data Acquisition and interpretation, Investigation, Writing- Original draft preparation .Rafael Alós Data Acquisition and interpretation, Investigation, Writing- Reviewing and Editing . Sebastiano Biondo Data Acquisition and interpretation, Investigation, WritingReviewing and Editing. Antonio Codina-Cazador Data Acquisition and interpretation, Investigation, Writing- Reviewing and Editing. José María Enríquez-Navascues Data Acquisition and interpretation, Investigation, Writing- Reviewing and Editing. Eloy EspínBasany Data Acquisition and interpretation, Investigation, WritingReviewing and Editing. José Vicente Roig-Vila Data Acquisition and interpretation, Investigation, Writing- Reviewing and Editing. Andrés Cervantes Conceptualization, Methodology, Data Acquisition and interpretation Investigation, Writing- Original draft preparation, Writing- Reviewing and Editing, Supervision. Eduardo García-Granero Conceptualization, Methodology, Data Acquisition and interpretation, Investigation, Writing- Original draft preparation, Writing- Reviewing and Editing, Supervision.

\section{Declaration of competing interest}

None declared.

\section{Acknowledgement}

The authors would like to thank Dr. Hector Ortiz for coordinating the Rectal Cancer Project (Viking) and this manuscript.

\section{Appendix A. Supplementary data}

Supplementary data to this article can be found online at https://doi.org/10.1016/j.ejso.2020.04.056.

\section{References}

[1] Luzietti E, Pellino G, Nikolaou S, et al. Comparison of guidelines for the management of rectal cancer. BJS Open 2018;2:433-45.

[2] Benson 3rd AB, Venook AP, Al-Hawary MM, et al. Rectal cancer, version 2.2018, NCCN clinical practice guidelines in oncology. J Natl Compr Canc Netw $2018 ; 16: 874-901$.

[3] Glynne-Jones R, Wyrwicz L, Tiret E, et al. Rectal cancer: ESMO Clinical Practice Guidelines for diagnosis, treatment and follow-up. Ann Oncol 2017;28: iv22-40.

[4] Peeters KC, van de Velde CJ, Leer JW, et al. Late side effects of shortcourse preoperative radiotherapy combined with total mesorectal excision for rectal cancer: increased bowel dysfunction in irradiated patients-a Dutch colorectal cancer group study. J Clin Oncol 2005;23:6199-206.

[5] Rahbari NN, Elbers H, Askoxylakis V, et al. Neoadjuvant radiotherapy for rectal cancer: meta-analysis of randomized controlled trials. Ann Surg Oncol 2013;20:4169-82.

[6] Nicholas S, Chen L, Choflet A, Fader A, Guss Z, Hazell S, et al. Pelvic radiation and normal tissue toxicity. Semin Radiat Oncol 2017:27:358-69.

[7] Glynne-Jones R. Looking for the Good, Bad and the Ugly rectal cancers of the twenty-first century... or "How to avoid tears when peeling onions". Tech Coloproctol 2017:21:577-9.

[8] van Gijn W, Marijnen CA, Nagtegaal ID, et al. Preoperative radiotherapy combined with total mesorectal excision for resectable rectal cancer: 12-year follow-up of the multicentre, randomised controlled TME trial. Lancet Oncol 2011:12:575-82.

[9] Wibe A, Møller B, Norstein J, et al. A national strategic change in treatment policy for rectal cancer-implementation of total mesorectal excision as routine treatment in Norway. A national Audit. Dis Colon Rectum 2002;45: 857-66.

[10] Dietz DW. Consortium for optimizing surgical treatment of rectal cancer (OSTRiCh). Multidisciplinary management of rectal cancer: the OSTRICH. J Gastrointest Surg 2013;17:1863-8.

[11] Ortiz H, Codina A. Rectal cancer project of the Spanish association of Surgeons (viking project): past and future. Cir Esp 2016;94:63-4.

[12] Von Elm E, Altman DG, Egger M, et al. The Strengthening the Reporting of Observational Studies in Epidemiology (STROBE) statement: guidelines for reporting observational studies. Lancet 2007;370:1453-7.

[13] Biondo S, Ortiz H, Lujan J, et al. Quality of mesorectum after laparoscopic resection for rectal cancer - results of an audited teaching programme in Spain. Colorectal Dis 2010;12:24-231.

[14] Ortiz H, Ciga MA, Armendariz P, et al. Multicentre propensity score-matched analysis of conventional versus extended abdominoperineal excision for low rectal cancer. Br J Surg 2014;101:874-81.

[15] Pellino G, Biondo S, Codina Cazador A, et al. Pelvic exenterations for primary rectal cancer: analysis from a 10-year national prospective database. World Gastroenterol 2018:24:5144-53.

[16] Mantel N. Chi-square tests with one degree of freedom; extensions of the Mantel-Haenszel procedure. J Am Stat Assoc 1963;58:690-700.

[17] Marinello FG, Frasson M, Baguena G, et al. Selective approach for upper rectal cancer treatment: total mesorectal excision and preoperative chemoradiation are seldom necessary. Dis Colon Rectum 2015;58:556-65.

[18] van den Broek CB, van Gijn W, Bastiaannet E, et al. Differences in preoperative treatment for rectal cancer between Norway, Sweden, Denmark, Belgium and The Netherlands. Eur J Surg Oncol 2014;40:1789-96.

[19] Gietelink L, Wouters MWJM, Marijnen CAM, et al. Changes in nationwide use of preoperative radiotherapy for rectal cancer after revision of the national colorectal cancer guideline. Eur J Surg Oncol 2017:43:1297-303.

[20] Frasson M, Garcia-Granero E, Roda D, et al. Preoperative chemoradiation may not always be needed for patients with T3 and T2N+ rectal cancer. Cancer 2011:117:3118-25.

[21] Taylor FG, Quirke P, Heald RJ, et al. Preoperative magnetic resonance imaging assessment of circumferential resection margin predicts disease-free survival and local recurrence: 5-year follow-up results of the MERCURY study. J Clin Oncol 2014;32:34-43.

[22] Asoglu O, Tokmak H, Bakir B, et al. The impact of total neo-adjuvant treatment on nonoperative management in patients with locally advanced rectal cancer: the evaluation of 66 cases. Eur J Surg Oncol 2020;46:402-9.

[23] Petrelli F, Trevisan F, Cabiddu M, et al. Total neoadjuvant therapy in rectal cancer: a systematic review and meta-analysis of treatment outcomes. Ann Surg 2020;271:440-8. 
[24] Kennedy ED, Simunovic M, Jhaveri K, et al. Safety and feasibility of using magnetic resonance imaging criteria to identify patients with "good prognosis" rectal cancer eligible for primary surgery: the phase 2 nonrandomized QuickSilver clinical trial. JAMA Oncol 2019;5:961-6.

[25] Battersby NJ, How P, Moran B, et al. Prospective validation of a low rectal cancer magnetic resonance imaging staging system and development of a local recurrence risk stratification model: the MERCURY II study. Ann Surg 2016;263:751-60.

[26] Nardone V, Reginelli A, Scala F, et al. Magnetic-resonance-Imaging texture analysis predicts early progression in rectal cancer patients undergoing neoadjuvant chemoradiation. Gastroenterol Res Pract 2019;2019:8505798.

Please cite this article as: Pellino G et al., Trends and outcome of neoadjuvant treatment for rectal cancer: A retrospective analysis and critical assessment of a 10-year prospective national registry on behalf of the Spanish Rectal Cancer Project, European Journal of Surgical Oncology, https://doi.org/10.1016/j.ejso.2020.04.056 